Int. J. Electrochem. Sci., 16 (2021) Article ID: 210666

International Journal of

ELECTROCHEMICAL

SCIENCE

$\underline{\text { www.electrochemsci.org }}$

\title{
Corrosion Inhibitive Action of Tenofovir Disproxil Fumarate (TDF) on Low Carbon Steel in $1 \mathrm{M} \mathrm{HCl}$
}

\author{
M. M. Mohamed ${ }^{1,6, ~ *, ~ B . ~ M . ~ P r a s a n n a ~}{ }^{2 *}$, Narayana Hebbar $^{3}$, Raiedahah Alsaiari $^{1}$, G. Banuprakash ${ }^{4}$, \\ M. R. Jagadessh ${ }^{5}$, Moustafa A. Rizk $k^{1,6}$ \\ ${ }^{1}$ Empty Quarter Research Unit, Department of Chemistry, College of science and art in Sharurah, \\ Najran University, Sharurah, Saudi Arabia \\ ${ }^{2}$ Department of Chemistry, Jain Institute of Technology, Davanagere, (Affiliated to Viswesaraya \\ Technological University, Belagavi), Karnataka, India \\ ${ }^{3}$ Department of Chemistry, S. D. M. College, Ujire, Dakshina Kannada, Karnataka, India \\ ${ }^{4}$ Department of Chemistry, S. J. B. Institute of Technology, Bangalore, Karnataka, India \\ ${ }^{5}$ Department of Physics, Jain Institute of Technology, Davanagere, Karnataka, India \\ ${ }^{6}$ Department of Chemistry of Science faculty, Suez Canal University, Ismailia 41522, Egypt \\ *E-mail: mmmohammad@nu.edu.sa (M. M. Mohamed), drbmprasanna@gmail.com (B M Prasanna)
}

doi: $10.20964 / 2021.06 .67$

Received: 5 March 2021 / Accepted: 20 April 2021 / Published: 30 April 2021

The effect of Tenofovir Disproxil Fumarate (TDF) on the corrosion of low carbon steel in $1 \mathrm{M} \mathrm{HCl}$ was investigated using theoretical and experimental methods at the temperature range of 303-333 $\mathrm{K}$. The electrochemical measurements such as polarization and impedance measurements suggested that the inhibition efficiencies increase with the increasing concentrations of TDF and decreases with the increase in temperature. The electrochemical potentiodynamic polarization measurement reveals that the TDF acts as a mixed type corrosion inhibitor for steel in $1 \mathrm{M} \mathrm{HCl}$. The overall increasing inhibition efficiency of an inhibitor is attributed to the adsorption onto the steel surfaces from the bulk of the solution. The adsorption process is the most appropriate fit with the Langmuir adsorption isotherm model, and computed thermodynamic parameters were discussed. Thermodynamic parameters reveal that the TDF adsorbs spontaneously onto the metal surfaces and retards the corrosion by the chemisorption method. The activation parameters explain the effect of temperature on TDF inhibition efficiency for low carbon steel in $1 \mathrm{M} \mathrm{HCl}$. The quantum chemical parameters strengthen the experimental results and are also a good agreement between them. Scanning electron microscopic measurement provides a visual idea of creating a protective layer on steel surfaces, which reduces corrosion.

Keywords: Corrosion inhibitors; TDF; Electrochemical; SEM; Quantum

FULL TEXT 
(C) 2021 The Authors. Published by ESG (www.electrochemsci.org). This article is an open access article distributed under the terms and conditions of the Creative Commons Attribution license (http://creativecommons.org/licenses/by/4.0/). 